\title{
ITUIUTABA (MG): reflexões sobre sua atuação na rede urbana regional a partir dos serviços de saúde e educação
}

\section{ITUIUTABA (MG): reflections on its role in the regional urban system through the health services and education}

\author{
Plínio Andrade Guimarães do Nascimento \\ Bolsista PIBIC/CNPq e acadêmico do Curso de Geografia da Faculdade Ciências Integradas do Pontal da \\ Universidade Federal de Uberlândia. E-mail: plinioufu@msn.com \\ Nágela Aparecida de Melo \\ Doutora em Geografia. Professora da Faculdade de Ciências Integradas do Pontal da Universidade \\ Federal de Uberlândia E-mail: nagela@ pontal.ufu.br
}

\begin{abstract}
RESUMO
Este trabalho tem como objetivo compreender o papel de Ituiutaba no sistema urbano regional por meio das interações espaciais estabelecidas pela presença dos serviços de saúde e educação. Para a elaboração deste artigo realizaram-se levantamentos e leituras de materiais bibliográficos sobre as temáticas cidades médias, sistema urbano brasileiro, serviços de saúde e educação e formação sócio-espacial de Ituiutaba. Além desses procedimentos, efetuaram-se coletas de dados primários e secundários sobre os serviços públicos e particulares de saúde e educação de Ituiutaba. As pesquisas teóricas e as análises dos dados permitiram analisar o papel singular desempenhado por Ituiutaba na rede urbana regional. Ao mesmo tempo, possibilitaram compreender que as interações espaciais estabelecidas por essa cidade, no contexto contemporâneo, ultrapassam a escala geográfica regional.

Palavras-Chave: Ituiutaba (MG). Hierarquia Urbana. Rede Urbana. Serviços de Saúde e Educação.
\end{abstract}

\begin{abstract}
This paper aims to understand the role of the regional urban system Ituiutaba through spatial interactions established by the presence health services and education. To prepare this article were carried out surveys and readings of bibliographic materials on the subject medium cities, the Brazilian urban system, health services and education and sociospatial formation of Ituiutaba. Beside these procedures were collected primary and secondary data about the services and private health and education of Ituiutaba. The theoretical research and analysis of data allowed us to analyze the unique role played by Ituiutaba on the regional urban network. At the same time, they made possible to understand the spatial interactions established by this city, in the contemporary context, beyond the regional geographic scale.
\end{abstract}

Keywords: Ituiutaba (MG). Urban Hierarchy. Urban Network. Services of Health and Education. 


\section{INTRODUÇÃO}

O presente artigo trata indiretamente do tema cidade média. Este assunto tem sido discutido por diversos estudiosos, de forma geral, destaca-se, entre os geógrafos, a afirmação de que as cidades médias se caracterizam pelo papel regional que exercem.

Santos (1993), Soares (1999, 2005), Santos e Silveira (2006), Sposito (2001), Amorim Filho e Rigotti (2002), Soares, Luz e Melo (2005), Sposito et al (2007), Corrêa (2007), entre outros, compartilham da idéia de que o papel regional é fator central na caracterização da cidade média brasileira. Segundo este princípio, a ligação regional é um dos papéis estratégicos das cidades médias. O elo regional é ao mesmo tempo fator de diferenciação entre as cidades médias e elemento que as identificam no contexto nacional e na rede urbana.

Conforme afirmou de Sposito et al (2007, p. 48), “[...] podemos caracterizar as 'cidades médias' afirmando que a classificação delas, pelo enfoque funcional, sempre esteve associada à definição de seus papéis regionais e ao potencial de comunicação e articulação proporcionado por suas situações geográficas".

Assim, com base nessa compreensão, realizou-se um estudo sobre a cidade de Ituiutaba (MG), o qual será apresentado ao longo deste artigo.

Especificamente, este trabalho tem como objetivo explicar o papel de Ituiutaba no sistema urbano regional, por meio da oferta dos serviços de saúde e educação prestados localmente. Além disso, visa analisar os impactos sócio-econômicos e espaciais relacionados à instalação do campus universitário da UFU na cidade de Ituiutaba.

A cidade de Ituiutaba é, portanto, o recorte espacial deste estudo. Esse centro urbano localiza-se na porção oeste da região do Triângulo Mineiro/AltoParanaíba (Mapa 1) e é sede do município de mesmo nome, que possui uma população total estimada de 96.759 habitantes, conforme dados do ano de 2009 (IBGE, 2010). 


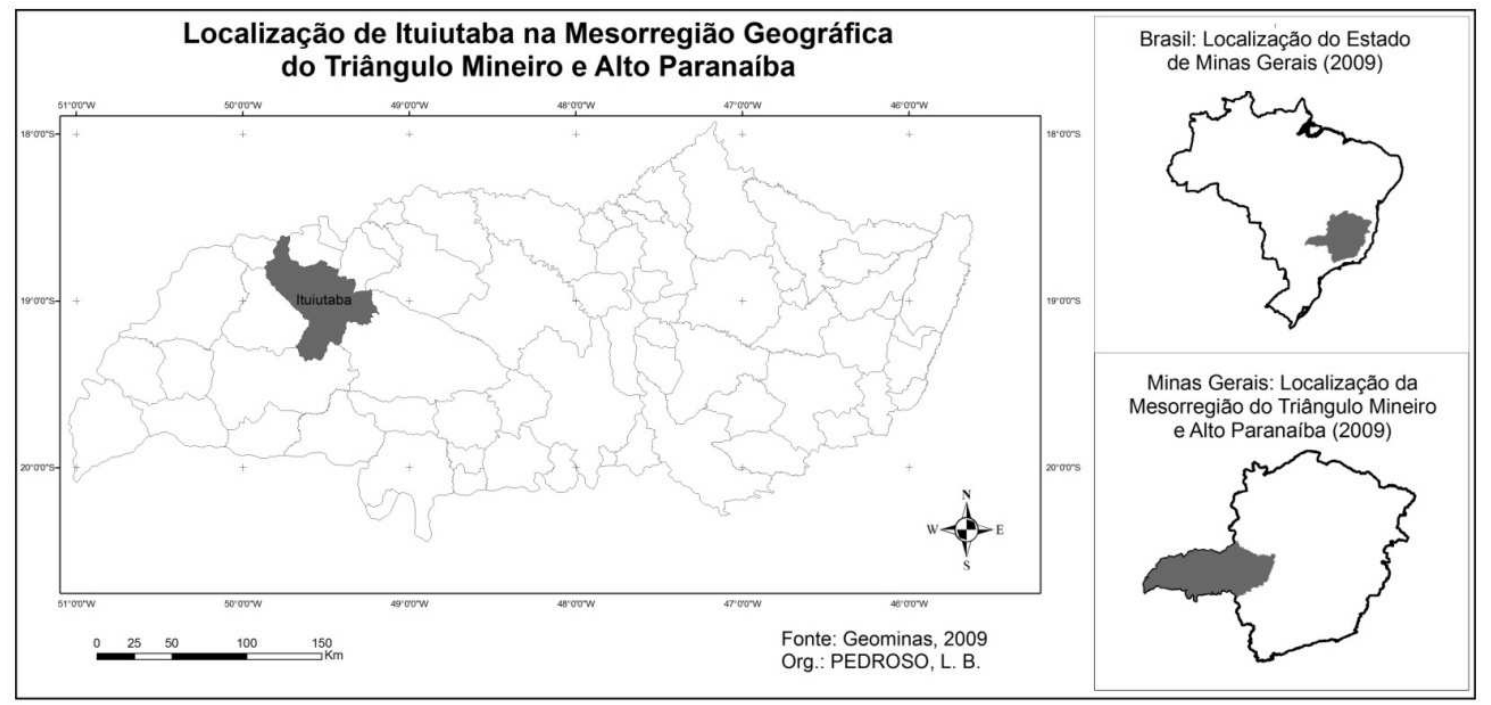

Mapa 1 - Município de Ituiutaba: localização na mesorregião geográfica do Triângulo Mineiro/Alto Paranaíba, 2009.Fonte: GEOMINAS, 2009. Org.: PEDROSO, L. B., 2009.

Ituiutaba, além de atender as demandas da população local, desempenha importante papel regional, sobretudo por meio de seu setor terciário e dos equipamentos urbanos que possui (OLIVEIRA, 2003; NASCIMENTO; MELO, 2010).

Inicialmente, a formação histórico-espacial e econômica de Ituiutaba e das demais cidades do Triângulo Mineiro associa-se às dinâmicas da pecuária tradicional, no século XIX. Segundo Soares (1995, p. 85),

\begin{abstract}
A rede urbana no Triângulo Mineiro nasce dependente da pecuária, e por isso, cria núcleos urbanos dispersos, uma vez que os latifúndios possuem grandes áreas e concentram sua força de trabalho na própria propriedade. As articulações internas são fragilizadas, predominantemente em função das baixas densidades demográficas e do pouco dinamismo econômico, limitado pela atividade pecuária.
\end{abstract}

Ituiutaba e as demais cidades da região que se formaram até meados do século XX enfrentaram dificuldades no que se refere ao estabelecimento de interações espaciais, uma vez que sua rede urbana regional era pouco complexa e de baixa dinamicidade em relação à circulação de pessoas, mercadorias, capitais e informações.

No entanto, à medida que foram ocorrendo emancipações territoriais e a consequente implantação e oficialização de novas cidades em áreas que pertenciam, anteriormente, ao município de Ituiutaba - como Santa Vitória, em 1948, Capinópolis, em 1953, Gurinhatã e Ipiaçu, em 1962 -, o sistema urbano da área do "Pontal do Triângulo Mineiro"1 foi-se constituindo (IBGE, 2009). Além disso, o sistema de 
transporte (as estradas e as linhas de ônibus) viabilizou a melhoria da articulação dos territórios e o desenvolvimento e ampliação dos fluxos regionais e inter-regionais.

O aumento da densidade de relações de Ituiutaba, na rede urbana, também está associado com as especializações produtivas que ocorreram no seu território, ao longo do processo histórico, pela atuação de agentes econômicos.

Os fluxos de mercadorias, pessoas e capitais que se originavam desse município e para ele convergiam, nas décadas de 1950 e 1960, relacionavam-se com a dinâmica da economia agrícola, cujo produto principal era o arroz.

Nos últimos anos, Ituiutaba vem recebendo novos agentes econômicos e equipamentos urbanos, especialmente relacionados ao setor do agronegócio e da educação (ensino superior e técnico). Esses elementos têm contribuído para consolidar a área de influência de Ituiutaba no espaço regional.

Este estudo trata, portanto, sobre a atuação regional de Ituiutaba, a partir dos órgãos públicos estaduais e federais existentes nessa cidade, dos serviços de saúde prestados e do ensino superior público ${ }^{2}$.

Considerou-se, nesta pesquisa, parte da metodologia proposta pela Rede de Pesquisadores sobre Cidades Médias $(\mathrm{ReCiMe})^{3}$. Especificamente, utilizaram-se parte das variáveis do Eixo I "Ramos de Atividades Econômicas Representativas da Atuação dos Novos Agentes Econômicos”, sendo: serviços de saúde especializados e ensino superior.

Este trabalho foi desenvolvido a partir de três etapas básicas. Inicialmente, realizou-se pesquisa bibliográfica sobre as temáticas cidade média, serviços de saúde e educação, sistema urbano brasileiro, hierarquia da rede urbana de Minas Gerais e formação sócio-espacial de Ituiutaba.

$\mathrm{Na}$ segunda etapa efetuaram-se as coletas de dados secundários. Coletaram-se informações estatísticas sobre as especialidades e os serviços médicos de Ituiutaba e dados relacionados ao sistema educacional dessa cidade, servindo-se de visitas técnicas em instituições públicas e particulares e de consultas nas páginas da Internet do Instituto Brasileiro de Geografia e Estatística (IBGE), do Departamento de Informática do Sistema Único de Saúde (DATASUS), da Secretaria de Estado de Saúde de Minas Gerais (SES/MG), do Ministério da Educação (MEC) e do Instituto Nacional de Estudos e Pesquisas Educacionais (INEP). 
$\mathrm{Na}$ terceira etapa realizou-se a investigação de campo que, por sua vez, constituiuse na atividade principal para a produção de dados e informações primárias. Esse procedimento foi desenvolvido valendo-se de estruturadas, questionários e de observação direta, realizados no primeiro semestre de $2010^{4}$.

Realizaram-se entrevistas com autoridades do serviço municipal de saúde de Ituiutaba e com representantes da administração municipal dos municípios de Cachoeira Dourada, Canápolis, Capinópolis, Gurinhatã, Ipiaçu, Monte Alegre de Minas, São Simão e Santa Vitória ${ }^{5}$.

Em relação aos questionários, foram aplicados 843 formulários desta natureza ${ }^{6}$ na Faculdade de Ciências Integradas do Pontal (FACIP/UFU), tendo como público alvo os alunos dos cursos de graduação dessa instituição.

A outra parte da pesquisa de campo consistiu na observação direta para a coleta de dados primários in loco sobre as instituições de ensino superior e os órgãos públicos existentes em Ituiutaba.

Os dados coletados foram sistematizados em tabelas, gráficos, mapas e quadros que estão apresentados e analisados nos próximos subitens.

\section{ITUIUTABA (MG): considerações sobre os serviços médicos ofertados pelas unidades de saúde no contexto regional}

A análise dos equipamentos e serviços médicos existentes nos diferentes níveis de atenção à saúde, em Ituiutaba, permite também (re)conhecer a importância que essa cidade desempenha no sistema urbano regional.

A cidade de Ituiutaba conta com uma rede de serviços médicos estruturados por meio da prestação de atendimentos ambulatoriais, hospitalares, laboratoriais e clínicos.

Entre os estabelecimentos existentes no setor de saúde, no ano de 2010, destacamse três hospitais (Hospital São José, Hospital Mater Dei e Hospital Nossa Senhora da Abadia), cinco laboratórios, 11 postos de saúde e 43 clínicas especializadas (LISTA SABE, 2010).

A cidade dispõe, principalmente, de serviços médicos que envolvem procedimentos de baixa e média complexidade. Há apenas duas especialidades médicas 
de alta complexidade - a unidade de tratamento intensivo (UTI) e a de hemodiálise. Entre os procedimentos de média complexidade existentes nesse sistema de saúde, no ano de 2010, destacam-se: exames ultrassonográficos, cirurgia geral, patologia clínica, anatomopatologia e citopatologia, dentre outros (CNES, 2010).

Neste sentido, o serviço de média complexidade

[...] é aquele que se propõe a realizar as ações de média complexidade e para tanto deve oferecer condições técnicas, instalações físicas, equipamentos e recursos humanos adequados ao atendimento às pessoas com risco ou suspeita para perda auditiva e pessoas portadoras de deficiência auditiva, de forma articulada e integrada com o sistema local e regional (BRASIL, 2007, p. 72).

Segundo Silva e Ramires (2009, p. 13-14):

Os serviços médicos de Alta Complexidade envolvem os seguintes
procedimentos: assistência ao paciente portador de doença renal crônica (por
meio dos procedimentos de diálise); assistência ao paciente com câncer;
cirurgia cardíaca e de veias; colocação de marca-passo; assistência em
problemas de ossos e articulações (juntas); procedimentos de neurocirurgia;
assistência em otologia; cirurgia de implante coclear; cirurgia das vias aéreas
superiores e da região cervical; cirurgia da calota craniana, da face e do
sistema estomatognático; procedimentos em lábio leporino; procedimentos
para avaliação e tratamento dos transtornos respiratórios do sono; assistência
aos pacientes portadores de queimadura; assistência aos pacientes portadores
de obesidade (cirurgia para emagrecer); cirurgia reprodutiva; genética clínica;
terapia nutricional; distrofia muscular progressiva; osteogênese imperfecta;
fibrose cística; reprodução assistida.

Embora os hospitais de Ituiutaba não tenham uma quantidade e diversidade significativa de procedimentos de alta complexidade, os hospitais São José, Mater Dei e Nossa Senhora D' Abadia, Pronto Socorro Municipal e os postos de atendimento de saúde exercem importante papel local e regional, por meio dos serviços médicos de baixa e média complexidade.

Ao analisar os serviços médicos prestados pelos profissionais no setor de saúde do Hospital São José, em 2009, notou-se que o número total de consultas, internações e exames de diagnóstico e terapia foi superior em relação aos mesmos atendimentos realizados pelos Hospitais Nossa Senhora D' Abadia e Mater Dei. Isso ocorre, entre outros motivos, por este ser o único hospital da cidade conveniado ao SUS (Quadro 4). 


\begin{tabular}{|c|c|c|c|c|}
\hline \multicolumn{5}{|c|}{$\begin{array}{l}\begin{array}{l}\text { Número de atendimentos realizado pelos hospitais Nossa Senhora D’ Abadia, São José } \\
\text { e Mater Dei }\end{array} \\
\end{array}$} \\
\hline $\begin{array}{l}\text { Serviços } \\
\text { Médicos }\end{array}$ & Plano de saúde & $\begin{array}{l}\text { Hospital N. S. } \\
\text { D' Abadia }\end{array}$ & $\begin{array}{l}\text { Hospital São } \\
\text { Jose }\end{array}$ & $\begin{array}{l}\text { Hospital } \\
\text { Mater Dei }\end{array}$ \\
\hline \multirow{4}{*}{ Consulta } & SUS & 0 & 8.742 & 0 \\
\hline & Particular & - & - & - \\
\hline & Particular/Convênio & 3.240 & - & - \\
\hline & Convênio & - & - & - \\
\hline \multirow{4}{*}{ Internações } & SUS & 0 & 4.613 & 354 \\
\hline & Particular & - & 233 & - \\
\hline & Particular/Convênio & 1.557 & - & 2.751 \\
\hline & Convênio & - & 145 & - \\
\hline \multirow{4}{*}{ Cirurgias } & SUS & 0 & 1.083 & 0 \\
\hline & Particular & - & - & - \\
\hline & Particular/Convênio & 1.130 & - & 1.220 \\
\hline & Convênio & - & - & - \\
\hline \multirow{4}{*}{$\begin{array}{l}\text { Atendimentos } \\
\text { de urgência e } \\
\text { emergência }\end{array}$} & SUS & 0 & 1.795 & - \\
\hline & Particular & - & - & - \\
\hline & Particular/Convênio & - & - & - \\
\hline & Convênio & - & - & - \\
\hline \multirow{4}{*}{$\begin{array}{lr}\text { Exames } & \text { de } \\
\text { diagnóstico } & \mathrm{e} \\
\text { terapia } & \end{array}$} & SUS & 0 & 2.661 & - \\
\hline & Particular & - & 176 & - \\
\hline & Particular/Convênio & - & - & - \\
\hline & Convênio & - & 143 & - \\
\hline
\end{tabular}

Quadro 4 - Ituiutaba (MG): número de atendimentos realizados pelos hospitais Nossa Senhora D' Abadia, São José e Mater Dei, 2009.

Fonte: PESQUISA DE CAMPO, 2010. Org.: NASCIMENTO, P. A. G., 2010.

(-) Traço indica que o hospital não teve os dados referentes ao número de atendimentos.

Dentre os procedimentos hospitalares oferecidos pelo Hospital Nossa Senhora D' Abadia, destacam-se os seguintes: ginecologia, ortopedia e traumatologia, otorrinolaringologia, cirurgia geral, oftalmologia, nefrologia e urologia, pneumologia, clínica geral, cardiologia, UTI adulto tipo I, obstetrícia cirúrgica e clínica, pediatria cirúrgica e clínica (CNES, 2010).

No que se refere aos atendimentos realizados pelos profissionais do hospital Mater Dei, verificou-se que, no ano de 2009, houve 354 internações realizadas por essa unidade de saúde em convênio com SUS e 2.751 internações por meio de convênios com planos médicos privados (Quadro 4).

Esses serviços médicos prestados pelo Mater Dei ainda são poucos, principalmente quando se compara com o Hospital São José, pelo fato de aquela unidade hospitalar não ter muitos leitos disponíveis e também de não ser conveniada com o SUS. 
Verificou-se que, dos três hospitais existentes na cidade de Ituiutaba, no ano de 2010, o São José é o mais antigo e também o que apresentou maior número de leitos em operação e mão-de-obra não especializada (Tabela 5).

Tabela 5 - Ituiutaba (MG): ano de fundação, número de leitos e funcionários especializados ou não, por hospital existente nesta cidade, 2009.

Ano de fundação, número de leitos e funcionários especializados ou não, por hospital

$\begin{array}{llll}\text { N. de N. de } & \text { N.de } & \text { Funcionários }\end{array}$

leitos leitos em funcionários não

Hospital $\quad$ Fundação em 2009 em 2009 em 2009 em 2009

\begin{tabular}{lllllc}
\hline Mater Dei & 1966 & 51 & 24 & 50 & - \\
Nossa S.D'Abadia & 1963 & 33 & 33 & 37 & 95 \\
São José & 1946 & 89 & 89 & 21 & 133 \\
\hline
\end{tabular}

Fonte: PESQUISA DE CAMPO, 2010. Org.: NASCIMENTO, P. A. G., 2010.

(-) Traço indica que o hospital não teve os dados referentes ao número de funcionários não especializados.

Deve-se reforçar que, dos três hospitais existentes em Ituiutaba, todos são administrados pelo setor privado; no entanto, o São José é a única unidade hospitalar que possui convênio com o SUS (PESQUISA DE CAMPO, 2010).

Por essas unidades hospitalares de Ituiutaba realizarem, principalmente, procedimentos de baixa e média complexidade, desempenham importante papel no sistema de saúde regional, pelos atendimentos médicos prestados aos pacientes residentes nessa cidade e nos municípios pactuados.

No plano de regionalização dos serviços de saúde do SUS, elaborado pela Secretaria de Estado da Saúde de Minas Gerais (2009), Ituiutaba foi caracterizada como uma microrregião de saúde pelo fato de atender os seguintes municípios mineiros: Ituiutaba, Cachoeira Dourada, Campina Verde, Canápolis, Capinópolis, Centralina, Gurinhatã, Ipiaçu e Santa Vitória.

A prestação do serviço público de saúde em Minas Gerais segue uma relação hierárquica específica. Assim, quando um paciente de um município da microrregião de saúde de Ituiutaba necessita de uma especialidade médica, principalmente de média a alta complexidade, a unidade de saúde de origem do paciente solicita esse procedimento para o SUS Fácil. Este sistema do governo estadual verifica a existência da 
especialidade médica e a disponibilidade de vagas no hospital conveniado com o SUS de Ituiutaba (Hospital São José), para o paciente receber o atendimento. Caso a unidade hospitalar não possua tal procedimento, o encaminhamento pode ser feito pelo Hospital São José ou pelo Pronto Socorro Municipal de Ituiutaba para a macrorregional de saúde, sendo esta, no caso, a cidade de Uberlândia, responsável pelos atendimentos ambulatoriais, hospitalares e clínicos especialmente de alta complexidade (PESQUISA DE CAMPO, 2010).

Em consonância com essa idéia, Silva e Ramires (2009, p. 52-53) explicaram que

A partir do PDRS/MG, 2003-2006, todos os municípios adstritos a essa região [de Ituiutaba] encaminhariam seus pacientes de alta complexidade para seu pólo macrorregional, preferencialmente. Deve-se destacar que, com base nos critérios de regionalização implementados a partir de 2003, procurou-se delegar para as microrregiões de saúde o atendimento da média complexidade, e, para as macrorregiões de saúde, a alta complexidade.

É importante, então, reforçar que a rede de serviços de saúde é estruturada de forma hierárquica e regionalizada, para que não haja concentração da demanda regional em uma única cidade. Ao verificar os serviços médicos oferecidos pelo SUS de Ituiutaba para os pacientes residentes nos municípios pactuados, no mês de dezembro de 2009, notou-se que Canápolis teve maior número total de cotas médicas, enquanto Cachoeira Dourada apresentou menor número de cotas médicas (Tabela 6).

Tabela 6 - Ituiutaba (MG): número de cotas médicas oferecidas pelo SUS dessa cidade para pacientes residentes nos municípios pactuados, dez/2009.

\begin{tabular}{lcccccc}
\hline \multicolumn{6}{c}{ Número de cotas médicas oferecidas pelo SUS para pacientes residentes nos } \\
municípios pactuados \\
\hline $\begin{array}{c}\text { Origem } \\
\text { (município) }\end{array}$ & Consultas & Exames & Internações & Cirurgias & Tratamentos & Outros \\
\hline Cachoeira & & & & & & \\
Dourada & 478 & 687 & 85 & 12 & 28 & 2 \\
Campina Verde & 481 & 1.733 & 25 & 16 & 10 & 3 \\
Canápolis & 1.087 & 3.676 & 158 & 57 & 58 & 1 \\
Capinópolis & 1.268 & 1.262 & 352 & 90 & 170 & 3 \\
Centralina & 711 & 1.662 & 685 & 41 & 62 & 1 \\
Gurinhatã & 758 & 2.181 & 96 & 81 & 66 & 1 \\
Ipiaçu & 952 & 1.156 & 71 & 28 & 47 & 4 \\
Santa Vitória & 629 & 2.222 & 97 & 45 & 79 & 1 \\
\hline Total & $\mathbf{6 . 8 9 6}$ & $\mathbf{1 4 . 5 7 9}$ & $\mathbf{1 . 5 6 9}$ & $\mathbf{3 7 0}$ & $\mathbf{5 2 0}$ & $\mathbf{1 2}$ \\
\hline
\end{tabular}

Fonte: SECRETARIA DE ESTADO DE SAÚDE DE MINAS GERAIS, Dez/2009. Org.: NASCIMENTO, P. A. G., 2010. 
A quantidade total de cotas para serviços médico-hospitalares são definidas pela verba repassada e pelos serviços solicitados ao SUS de Ituiutaba pelos municípios que formam a sua microrregião de saúde. (Tabela 7). Assim, como pode ser observado na tabela 6 e 7, Capinópolis e Centralina pagaram maior valor ao SUS de Ituiutaba, no mês de dezembro de 2009; no entanto, tiveram menor número de cotas médicas totais disponíveis, quando se compara com Canápolis. Acredita-se que os investimentos realizados pelos gestores desses dois municípios tenham priorizado procedimentos de maiores custos financeiros, determinando assim o menor número total de cotas médicas, quando comparados com outros municípios.

Tabela 7 - Ituiutaba (MG): verba repassada ${ }^{8}$ ao SUS desta cidade pelos municípios pactuados e população estimada, 2009.

\begin{tabular}{l|cc}
\hline \multicolumn{2}{c}{$\begin{array}{c}\text { Verba repassada ao SUS de Ituiutaba pelos municípios } \\
\text { pactuados e população estimada }\end{array}$} \\
\hline \multicolumn{1}{c}{$\begin{array}{c}\text { Município } \\
\text { pactuado }\end{array}$} & \multicolumn{2}{c}{$\mathbf{2 0 0 9}$} \\
\cline { 2 - 3 } & Verba repassada & População estimada \\
\hline Cachoeira Dourada & 55.284 .15 & 2.595 \\
Campina Verde & 36.021 .20 & 19.201 \\
Capinópolis & 220.603 .46 & 16.043 \\
Canápolis & 129.172 .50 & 11.865 \\
Centralina & 355.272 .13 & 10.557 \\
Gurinhatã & 83.810 .33 & 6.228 \\
Ipiaçu & 61.427 .51 & 4.374 \\
Santa Vitória & 75.616 .72 & 15.791 \\
\hline Total & $\mathbf{1 0 1 . 7 2 0 . 8 0 0}$ & $\mathbf{8 6 . 6 5 4}$ \\
\hline
\end{tabular}

Fonte: SECRETARIA DE ESTADO DE SAÙDE, 2010. IBGE - CIDADES@, 2009. Org.: NASCIMENTO, P. A. G., 2010

É importante ressaltar que os municípios pactuados ao SUS dessa cidade não podem ultrapassar os $10 \%$ das cotas médicas totais pré-estabelecidas por mês. Além disso, as cotas médicas não correspondem, necessariamente, aos atendimentos médicos realizados, mas sim à disponibilidade de vagas por consultas, exames, internações, cirurgias, dentre outros serviços médicos que foram pactuados (PESQUISA DE CAMPO, 2010).

Os dados do número de leitos e de equipamentos de saúde $^{9}$ de Ituiutaba, comparados com municípios pactuados, demonstram que o sistema de saúde dessa 
idade é mais bem equipado e evidenciam o seu papel regional no atendimento à saúde (Tabela 8). 
Tabela 8 - Ituiutaba (MG): comparativo do número de leitos e equipamentos de saúde existentes em relação aos municípios pactuados, 2009.

\begin{tabular}{|c|c|c|c|c|c|c|c|c|c|c|}
\hline \multicolumn{11}{|c|}{ Comparativo do número de leitos e equipamentos de saúde existentes em relação aos municípios pactuados } \\
\hline Descrição & $\begin{array}{l}\text { Cachoeira } \\
\text { Dourada }\end{array}$ & $\begin{array}{c}\text { Campina } \\
\text { Verde }\end{array}$ & Canápolis & Capinópolis & Centralina & Gurinhatã & Ipiaçu & Ituiutaba & $\begin{array}{c}\text { Santa } \\
\text { Vitória } \\
\end{array}$ & Total \\
\hline Leitos Cirúrgicos & 0 & 9 & 5 & 4 & 3 & 4 & 1 & 45 & 4 & 75 \\
\hline Leitos Clínicos & 0 & 15 & 9 & 6 & 8 & 11 & 3 & 51 & 19 & 122 \\
\hline Leitos Obstétricos & 0 & 6 & 3 & 7 & 2 & 4 & 2 & 19 & 5 & 48 \\
\hline Leitos Pediátricos & 0 & 5 & 4 & 3 & 0 & 8 & 1 & 22 & 4 & 47 \\
\hline $\begin{array}{l}\text { Equip. de diagnóstico através de } \\
\text { imagem }\end{array}$ & 2 & 6 & 1 & 2 & 0 & 2 & 2 & 45 & 7 & 67 \\
\hline Equipamentos odontológicos & 3 & 7 & 27 & 5 & 6 & 7 & 2 & 100 & 12 & 169 \\
\hline Equipamentos por métodos óticos & 0 & 0 & 0 & 0 & 0 & 1 & 0 & 10 & 0 & 11 \\
\hline $\begin{array}{l}\text { Equipamentos por métodos } \\
\text { gráficos }\end{array}$ & 1 & 3 & 2 & 3 & 3 & 2 & 1 & 20 & 3 & 38 \\
\hline $\begin{array}{l}\text { Equipamentos para manutenção da } \\
\text { vida }\end{array}$ & 6 & 9 & 15 & 19 & 9 & 5 & 4 & 144 & 17 & 228 \\
\hline $\begin{array}{l}\text { Mamógrafos com comando } \\
\text { simples }\end{array}$ & 0 & 1 & 0 & 0 & 0 & 0 & 0 & 1 & 0 & 2 \\
\hline Mamógrafos com estereotáxia & 0 & 0 & 0 & 0 & 0 & 0 & 0 & $\mathbf{0}$ & 0 & $\mathbf{0}$ \\
\hline Tomógrafo Computadorizado & 0 & 0 & 0 & 0 & 0 & 0 & 0 & 1 & 0 & 1 \\
\hline Eletrocardiógrafos & 1 & 3 & 2 & 3 & 3 & 2 & 1 & 17 & 3 & 35 \\
\hline Ultrassom doppler colorido & 0 & 1 & 0 & 0 & 0 & 1 & 0 & 9 & 0 & 11 \\
\hline Ultrassom ecógrafo & 0 & 1 & 0 & 0 & 0 & 0 & 0 & 3 & 1 & 5 \\
\hline Eletroencefalógrafos & 0 & 0 & 0 & 0 & 0 & 0 & 0 & 3 & 0 & 3 \\
\hline Equipamentos de hemodiálise & 0 & 0 & 0 & 0 & 0 & 0 & 0 & 16 & 0 & 16 \\
\hline Raio X para densitometria óssea & 0 & 0 & 0 & 0 & 0 & 0 & 0 & 1 & 0 & 1 \\
\hline Raio $X$ até $100 \mathrm{~mA}$ existentes & 1 & 1 & 0 & 0 & 0 & 1 & 1 & 3 & 1 & 8 \\
\hline Raio X de 100 a $500 \mathrm{~mA}$ & 0 & 1 & 1 & 1 & 0 & 0 & 0 & 3 & 2 & 8 \\
\hline Raio X mais de $500 \mathrm{~mA}$ & 0 & 0 & 0 & 0 & 0 & 0 & 0 & 1 & 0 & 1 \\
\hline
\end{tabular}


Fonte: DATASUS, 2009. Org.: NASCIMENTO, P. A. G., 2010.

Geo UERJ - Ano 13, nº. 22, v. 2, 2º semestre de 2011 p. 395-421 - ISSN 1981-9021 http://www.e-publicacoes.uerj.br/index.php/geouerj 
Verificou-se também que, em 2009, Ituiutaba se destacou no setor de saúde, entre os municípios pactuados, por possuir equipamentos de alta complexidade, como um mamógrafo com comando simples, um tomógrafo computadorizado e um raio-X para densitometria óssea, além de 16 aparelhos de hemodiálise (Tabela 8).

Desta forma, o sistema de saúde de Ituiutaba oferece possibilidades variadas de prestação de serviços de saúde públicos e privados e de baixa e média complexidade, especialmente para os moradores locais e dos municípios de menor porte demográfico da porção oeste da Mesorregião Triângulo Mineiro.

ITUIUTABA (MG): caracterização do sistema educacional e análise do papel regional por meio do serviço público de educação superior.

A cidade de Ituiutaba, atualmente, conta com redes públicas e privadas do ensino básico e superior que prestam serviços para a população local e regional.

Especificamente, no ano de 2009, verificou-se, nesse município, a existência de um número total de 80 instituições de ensino e 1.118 docentes, distribuídos desde o sistema pré-escolar até o ensino médio (Tabela 9).

Tabela 9 - Ituiutaba (MG): número de instituições e docentes por nível de ensino, 2009.

\begin{tabular}{lcc}
\hline \multicolumn{3}{c}{ Número de instituições e docentes por nível de ensino } \\
\hline \multicolumn{1}{c}{ Nível de ensino } & N. de Instituições & N. de Docentes \\
\hline Pré-escolar público municipal & 17 & 94 \\
Pré-escolar público estadual & 0 & 0 \\
Pré-escolar público federal & 0 & 0 \\
Pré-escolar privado & 15 & 51 \\
Ensino fundamental público & & \\
municipal & 16 & 303 \\
Ensino fundamental público & & \\
estadual & 13 & 334 \\
Ensino fundamental público & & \\
federal & 0 & 0 \\
Ensino fundamental privado & 9 & 129 \\
Ensino médio público estadual & 4 & 130 \\
Ensino médio público federal & 0 & 0 \\
Ensino médio público municipal & 2 & 25 \\
Ensino médio privado & 4 & $\mathbf{1 . 1 1 8}$ \\
\hline \multicolumn{1}{c}{ Total } & $\mathbf{8 0}$ & $1981-92$
\end{tabular}

Geo UERJ - Ano 13, nº. 22, v. 2, 2º semestre de 2011 p. 395-421 - ISSN 1981-9021 http://www.e-publicacoes.uerj.br/index.php/geouerj 
Fonte: IBGE - CIDADES @ , 2009. Org.: NASCIMENTO, P. A. G., 2010.

Com relação ao número de matrículas, por nível de ensino, entre os anos de 2000 e 2009 verificou-se que houve uma queda no número total de matrículas, em todas as fases da educação básica (Tabela 10).

Tabela 10 - Ituiutaba (MG): número de matrículas, 2000 a 2009.

\begin{tabular}{|c|c|c|c|c|c|c|}
\hline \multirow[b]{2}{*}{ Matrículas } & \multicolumn{3}{|c|}{ Número de matrículas (2000) } & \multicolumn{3}{|c|}{ Número de matrículas (2009) } \\
\hline & $\begin{array}{c}\text { Ensino } \\
\text { Pré- } \\
\text { escolar }\end{array}$ & $\begin{array}{c}\text { Ensino } \\
\text { Fundamental }\end{array}$ & $\begin{array}{l}\text { Ensino } \\
\text { Médio }\end{array}$ & $\begin{array}{c}\text { Ensino } \\
\text { Pré- } \\
\text { escolar }\end{array}$ & $\begin{array}{c}\text { Ensino } \\
\text { Fundamental }\end{array}$ & $\begin{array}{l}\text { Ensino } \\
\text { Médio }\end{array}$ \\
\hline Público Estadual & 0 & 9.540 & 4.419 & 0 & 6.449 & 3.201 \\
\hline $\begin{array}{l}\text { Público Federal } \\
\text { Público }\end{array}$ & 0 & 0 & 0 & 0 & 0 & 0 \\
\hline Municipal & 1.349 & 5.199 & 611 & 1.339 & 5.460 & 210 \\
\hline Privado & 1.434 & 1.478 & 299 & 542 & 1.291 & 397 \\
\hline Total & 2.783 & 16.217 & 5.329 & 1.881 & 13.200 & 3.808 \\
\hline
\end{tabular}

Fonte: MINISTÉRIO DA EDUCAÇÃO, 2000-2009. INSTITUTO NACIONAL DE ESTUDOS E PESQUISAS EDUCACIONAIS ANÍSIO TEIXEIRA, 2000-2009. Org.: NASCIMENTO, P. A. G., 2010.

Notou-se também que, nesse período, o número de matrículas nas escolas públicas estaduais do Ensino Fundamental diminuiu mais do que no sistema de ensino privado (Tabela 10).

A cidade conta, ainda, com quatro instituições de ensino superior e um total de 75 cursos, sendo destes 32 de graduação, 13 tecnológicos de nível superior e 30 de pósgraduação lato sensu, conforme dados apresentados na tabela 11.

Tabela 11 - Ituiutaba (MG): universidades, faculdades e número de cursos existentes, 2010 .

\begin{tabular}{lccccc}
\hline \multirow{2}{*}{ Universidades/Faculdades } & \multicolumn{5}{c}{ Número de cursos existentes } \\
\cline { 2 - 7 } & Graduação & $\begin{array}{c}\text { Tecnológicos } \\
\text { (Nível } \\
\text { superior) }\end{array}$ & $\begin{array}{c}\text { Pós- } \\
\text { graduação } \\
\text { lato sensu }\end{array}$ & $\begin{array}{c}\text { Pós- } \\
\text { graduação } \\
\text { stricto sensu }\end{array}$ & $\begin{array}{c}\text { Total por } \\
\text { instituição }\end{array}$ \\
\hline Fundação Educacional de Ituiutaba & 11 & 4 & 12 & 0 & $\mathbf{2 7}$ \\
Universidade Norte do Paraná & 7 & 9 & 15 & 0 & $\mathbf{3 1}$ \\
Faculdade de Ciências Integradas do Pontal & 11 & 0 & 1 & 0 & $\mathbf{1 2}$ \\
Faculdade Triângulo Mineiro & 3 & 0 & 2 & 0 & $\mathbf{5}$ \\
\hline \multicolumn{1}{c}{ Total } & $\mathbf{3 2}$ & $\mathbf{1 3}$ & $\mathbf{3 0}$ & 0 & $\mathbf{7 5}$ \\
\hline
\end{tabular}

Fonte: FTM, 2010. FEIT, 2010. UNOPAR, 2010. FACIP/UFU, 2010.

Org.: NASCIMENTO, P. A. G., 2010. 
Com relação aos cursos oferecidos pelas instituições de ensino superior existentes em Ituiutaba, no ano de 2010, destaca-se que a Universidade Norte do Paraná (UNOPAR) tem maior número de cursos tecnológicos e de pós-graduação lato sensu, especialmente quando se compara com as outras faculdades (Tabela 11). Deve-se lembrar que a UNOPAR é a única rede de ensino superior virtual existente nessa cidade, com aulas por meio de recursos tecnológicos (via satélite e Internet).

Além disso, os serviços de educação, em Ituiutaba, têm importância no cenário regional também pela oferta de cursos técnicos, de capacitação profissional e de idiomas (Quadro 5).

\begin{tabular}{|c|c|}
\hline Nome da Instituição de Ensino/ tipo de formação & $\begin{array}{c}\text { Quantidade } \\
\text { modalidades } \\
\text { de cursos }\end{array}$ \\
\hline \multicolumn{2}{|l|}{ Escola de idiomas } \\
\hline ALL & 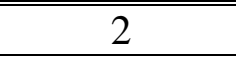 \\
\hline CCAA & 2 \\
\hline Cultura Inglesa & 2 \\
\hline Wizard & 5 \\
\hline \multicolumn{2}{|l|}{ Cursos Técnicos } \\
\hline $\begin{array}{l}\text { Instituto Federal de Educação, Ciência e Tecnologia do Triângulo } \\
\text { Mineiro (IFTM) }\end{array}$ & 2 \\
\hline Serviço Nacional de Aprendizagem Industrial (SENAI) & 2 \\
\hline Serviço Nacional de Aprendizagem Comercial (SENAC) & 1 \\
\hline \multicolumn{2}{|l|}{ Cursos de Aprendizagem } \\
\hline Serviço Nacional de Aprendizagem Industrial (SENAI) & 8 \\
\hline \multicolumn{2}{|l|}{ Cursos de Qualificação e Aperfeiçoamento } \\
\hline Serviço Nacional de Aprendizagem Industrial (SENAI) & 13 \\
\hline \multicolumn{2}{|l|}{ Cursos de Capacitação } \\
\hline Serviço Nacional de Aprendizagem Comercial (SENAC) & 9 \\
\hline \multicolumn{2}{|l|}{ Cursos Técnicos por meio da Educação a Distância } \\
\hline Serviço Nacional de Aprendizagem Comercial (SENAC) & 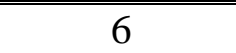 \\
\hline
\end{tabular}

Quadro 5 - Ituiutaba (MG): cursos de idiomas, técnicos, de aprendizagem, qualificação e aperfeiçoamento profissional presencial e a distância, 2010.

Fonte: ALL, 2010. CCAA, 2010. CULTURA INGLESA, 2010. IFTM, 2010. SENAC, 2010. SENAI, 2010. PESQUISA DE CAMPO, 2010. Org.: NASCIMENTO, P. A. G., 2010.

A educação básica, a técnica e a superior são elementos que, juntos, contribuem para o processo de reestruturação interurbana e intraurbana de Ituiutaba. 
A existência principalmente das instituições de ensino superior promove uma maior capacidade de polarização do espaço regional por essa cidade. Assim, Ituiutaba recebe, de segunda a terça-feira, 18 ônibus de estudantes, provenientes dos municípios de Capinópolis, Santa Vitória, São Simão, Ipiaçu, Canápolis, Cachoeira Dourada, Gurinhatã e Monte Alegre de Minas, atraídos, principalmente, pelos cursos superiores (Tabela 12). Além disso, as prefeituras de Canápolis e Cachoeira Dourada também cedem, de segunda a sexta-feira, um micro-ônibus de estudantes, e Capinópolis oferece uma van com destino a Ituiutaba, com a finalidade de transportar estudantes.

Tabela 12 - Ituiutaba (MG): número de ônibus que transportam estudantes de outros municípios para esta cidade, 2010.

\begin{tabular}{|c|c|c|c|}
\hline \multicolumn{4}{|c|}{$\begin{array}{c}\text { Número de ônibus que transportam estudantes de outros municípios para esta } \\
\text { cidade }\end{array}$} \\
\hline Município & $\begin{array}{c}\text { N. de } \\
\text { ônibus } \\
\text { diário } \\
\text { (segunda } \\
\text { a sexta- } \\
\text { feira) }\end{array}$ & $\begin{array}{c}\text { N. de } \\
\text { ônibus } \\
\text { semanal } \\
\text { (uma } \\
\text { vez ao } \\
\text { sábado) }\end{array}$ & Motivo \\
\hline Capinópolis & 6 & 0 & Ensino Superior, Tecnológico e Técnico \\
\hline Santa Vitória & 3 & 0 & Ensino Superior, Tecnológico e Técnico \\
\hline São Simão & 2 & 1 & Ensino Superior \\
\hline Ipiaçu & 2 & 0 & Ensino Superior \\
\hline Canápolis & 2 & 0 & Ensino Superior \\
\hline Cachoeira Dourada & 1 & 0 & Ensino Superior e Cursos Técnicos \\
\hline Gurinhatã & 1 & 0 & Ensino Superior e Cursos Técnicos \\
\hline Monte Alegre de Minas & 1 & 0 & Ensino Superior \\
\hline Total & 18 & 1 & - \\
\hline
\end{tabular}
Fonte: PESQUISA DE CAMPO, 2010. Org.: NASCIMENTO, P. A. G., 2010.

Os dados apresentados na tabela 12 evidenciam a intensidade do fluxo de estudantes de municípios relativamente próximos a Ituiutaba, que buscam essa cidade para se qualificarem profissionalmente em cursos técnicos, tecnológicos e superiores.

Nesse sentido, merece destaque a recente implantação de duas instituições federais de ensino na cidade de Ituiutaba - a Faculdade de Ciências Integradas do Pontal, extensão da Universidade Federal de Uberlândia (FACIP/UFU), e o Instituto Federal de Educação, Ciência e Tecnologia do Triângulo Mineiro (IFTM). 
Essas instituições têm promovido mudanças de ordem cultural, econômica e espacial em Ituiutaba e potencializado a capacidade desta de atrair estudantes da região do Triângulo Mineiro e de outras partes do país.

Especificamente, este estudo se limita-se à análise dos principais impactos da atuação da FACIP/UFU na cidade de Ituiutaba e no seu papel na rede urbana.

Neste caso, a análise da origem dos estudantes da FACIP/UFU, segundo o local de residência no momento anterior ao ingresso nessa unidade acadêmica, é um indicador importante, pois evidencia o alcance da área de influência da cidade de Ituiutaba.

Tendo isso em vista, foram aplicados 843 questionários de pesquisa com os alunos de todos os cursos de graduação da FACIP/UFU. Destaca-se que, desse total, 494 estudantes, ou seja, 58,60 \% do universo pesquisado, declararam que, antes de ingressarem nessa instituição de ensino superior, moravam em Ituiutaba. E os demais 349 que responderam os questionários $(41,40 \%$ do total) afirmaram que não residiam nessa cidade ou no município quando ingressaram nos cursos superiores da FACIP/UFU (Gráfico 1).

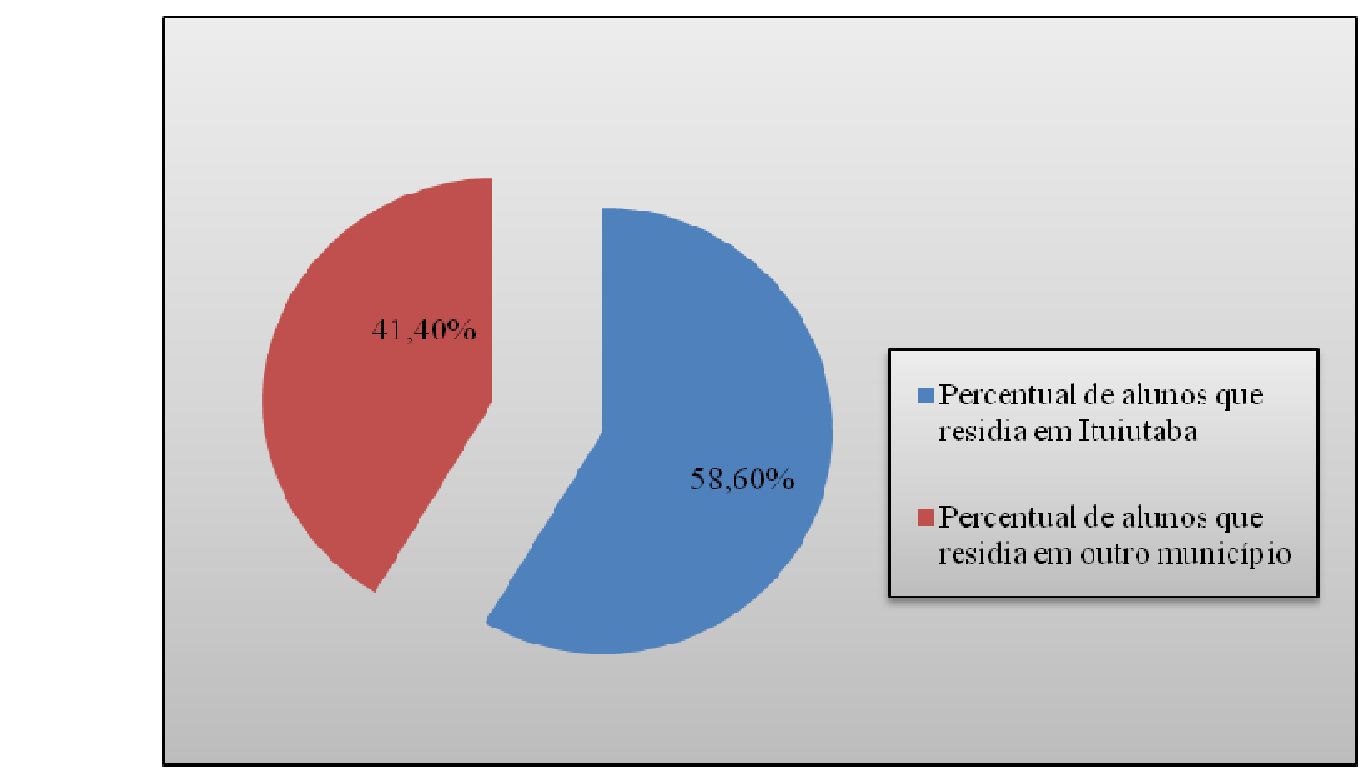

Gráfico 1 - Ituiutaba (MG): percentual de alunos segundo local de residência antes do ingresso FACIP/UFU, 2010.

Fonte: PESQUISA DE CAMPO, 2010. Org.: NASCIMENTO, P. A. G., 2010. 
Os dados dos questionários demonstram que, dos 349 estudantes da FACIP/UFU que não residiam na cidade de Ituiutaba no momento do ingresso nessa faculdade, 264 eram moradores de municípios da mesorregião Triângulo Mineiro/Alto Paranaíba (Gráfico 2). Do número total de alunos que vieram de municípios dessa mesorregião, destaca-se que: 72 alunos residiam em Uberlândia, 44 alunos residiam em Capinópolis, 27 alunos em Monte Alegre de Minas, 21 alunos residiam em Santa Vitória, 19 alunos residiam em Canápolis, 17 alunos residiam em Gurinhatã (PESQUISA DE CAMPO, 2010).

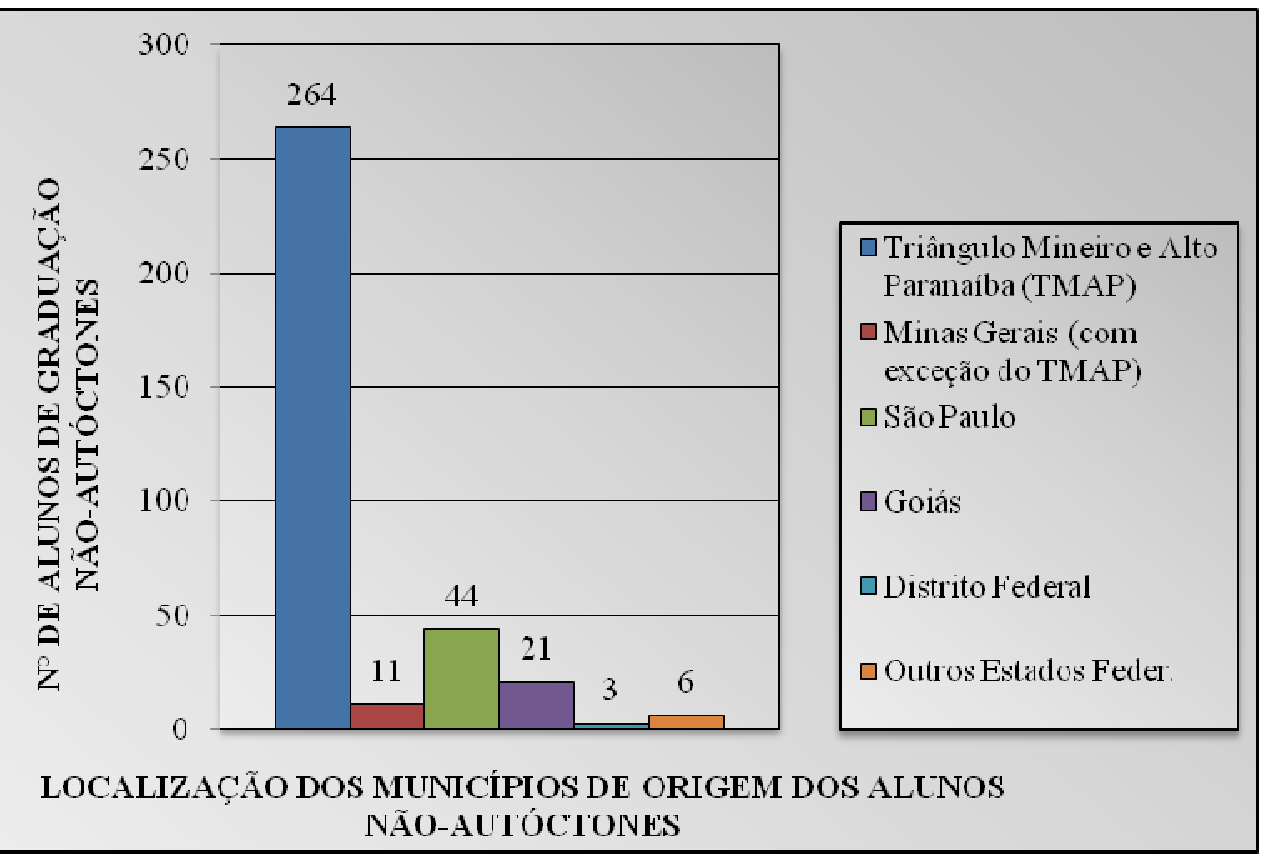

Gráfico 2 - Ituiutaba (MG): número de alunos de graduação da FACIP/UFU, nãoautóctones, segundo local de residência no momento do ingresso na instituição, 2010. Fonte: PESQUISA DE CAMPO, 2010. Org.: NASCIMENTO, P. A. G., 2010.

Dos 349 alunos que estudam na FACIP/UFU e que não residiam em Ituiutaba no ano do ingresso nessa faculdade, 30,95\% continuam residindo nos mesmos locais do momento do ingresso e/ou em outra localidade que não é Ituiutaba, enquanto que cerca de $69 \%$ se mudaram para essa cidade (Tabela 13). 
Tabela 13 - Ituiutaba (MG): alunos que no momento do ingresso na FACIP/UFU não residiam em Ituiutaba, segundo local residência em maio e junho de 2010.

\begin{tabular}{l|cc}
\hline \multicolumn{2}{c}{$\begin{array}{c}\text { Alunos que no momento do ingresso na FACIP/UFU não residiam em } \\
\text { Ituiutaba }\end{array}$} \\
\hline \multirow{2}{*}{$\begin{array}{c}\text { Município onde residiam em maio e junho } \\
\text { de 2010 }\end{array}$} & $\begin{array}{c}\text { Valor } \\
\text { absoluto }\end{array}$ & Valor relativo \\
\cline { 2 - 3 } Ituiutaba & 241 & 69 \\
Capinópolis & 35 & 10 \\
Monte Alegre de Minas & 18 & 5,2 \\
Canápolis & 16 & 4,6 \\
Santa Vitória & 13 & 3,7 \\
Ipiaçu & 7 & 2 \\
Gurinhatã & 6 & 1,7 \\
São Simão & 5 & 1,4 \\
Uberlândia & 3 & 0,9 \\
Cachoeira Dourada & 2 & 0,6 \\
- (os alunos não informaram) & 3 & 0,9 \\
\hline Total & $\mathbf{3 4 9}$ & $\mathbf{1 0 0}$ \\
\hline \multicolumn{1}{c}{ Fonte: PESQUISA DE CAMPO, 2010. Org.: NASCIMENTO, P. A. G., 2010. }
\end{tabular}

Assim, notam-se dois outros indicadores que expressam o impacto da instalação da instituição de ensino superior federal na cidade de Ituiutaba: um que diz respeito à existência de fluxos regulares de pessoas de outras localidades e outro que se refere a mudanças mais diretas na economia local, pelo acréscimo de novos moradores e consumidores.

Os fluxos pendulares de pessoas, realizados em busca de serviços ou para o exercício do trabalho, são dados essenciais para se entender as interações espaciais estabelecidas por Ituiutaba com outras localidades.

Especificamente, dos alunos da FACIP/UFU que foram entrevistados nesta pesquisa, 108 declaram que fazem deslocamentos frequentes de seus locais de residência para a cidade de Ituiutaba, em função dos serviços educacionais.

A realização de viagens diárias foi declarada por 88 alunos que se deslocam de suas cidades para Ituiutaba todos os dias, no período de segunda a sexta-feira (Mapa 2). 


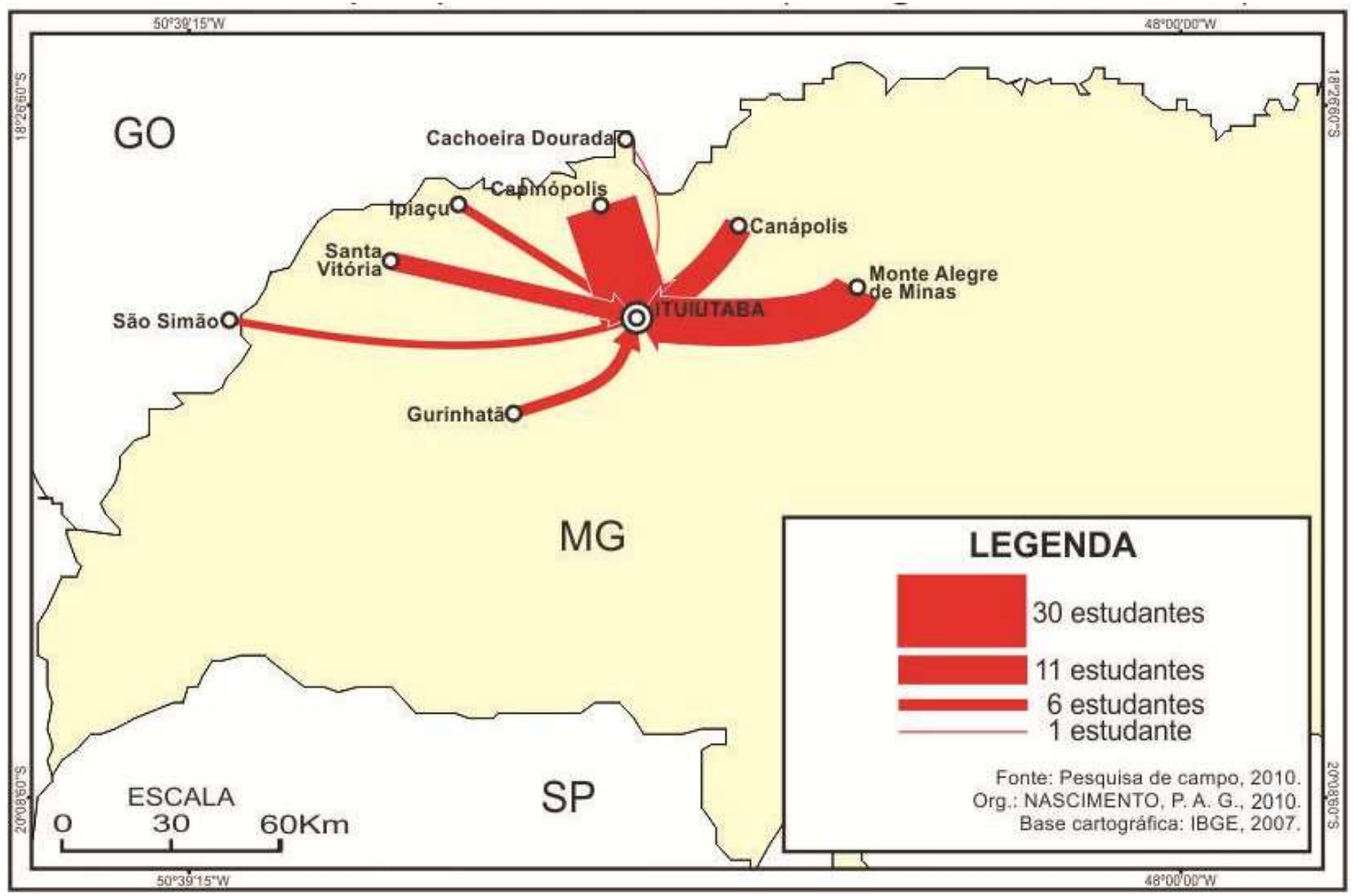

Mapa 2 - Ituiutaba (MG): número de estudantes de graduação da FACIP/UFU que se deslocam para esta cidade todos os dias, no período de segunda a sexta-feira, 2010.

Fonte: PESQUISA DE CAMPO, 2010. Org.: NASCIMENTO, P. A. G., 2010.

Outros 16 alunos dessa instituição afirmaram que se deslocam de seus municípios de origem em direção a Ituiutaba todos os dias, no período de segunda-feira a sábado. Esses universitários são originários de Capinópolis, Canápolis, Santa Vitória, Ipiaçu e São Simão ${ }^{10}$.

Os dados do mapa 2 demonstram que os fluxos diários para Ituiutaba não são provenientes apenas dos municípios de sua microrregião; envolvem estudantes de outros municípios, como Monte Alegre de Minas e Canápolis, os quais fazem parte da microrregião geográfica de Uberlândia; além destes, incluem-se também acadêmicos de São Simão, município localizado no estado de Goiás.

As distâncias dos fluxos de estudantes para Ituiutaba, considerando o local de origem, variam de 37,2 km (de Capinópolis) a 126 km (que é o caso de São Simão) (GOOGLE MAPS, 2010).

Pode-se concluir, segundo Soares et al (2010, p. 217), que as presenças de instituições de ensino, com destaque para o nível superior, 
[...] criam novas possibilidades de ação, produção e realização nas cidades em que se instalam, visto que são estimuladoras do desenvolvimento regional, por meio da oferta de subsídio e aporte de dados pelas pesquisas, bem como qualificam e especializam a força de trabalho, formando profissionais aptos a atuar em funções específicas.

Além disso, verifica-se que os órgãos que prestam serviços de ensino superior, principalmente os públicos, provocam o fortalecimento do papel regional e a ampliação da área de influência das cidades onde atuam. Isso foi verificado no caso de Ituiutaba. Especificamente, a partir da atuação da FACIP/UFU, essa cidade aumentou a sua importância no contexto regional da mesorregião do Triângulo Mineiro/Alto Paranaíba - e não apenas na área de abrangência da microrregião de Ituiutaba - e já apresenta alguma inserção extra-regional, ainda que pequena.

Por outro lado, os alunos que passaram a residir em Ituiutaba, por causa da FACIP/UFU - os migrantes universitários -, e aqueles que frequentam essa cidade por causa dessa instituição são agentes que ampliam as demandas de consumo de bens e serviços, localmente. Em consonância com essa idéia, Souza e Brumes (2006, p. 146) consideraram que as instituições de ensino superior estimulam fortemente o crescimento de migrantes universitários em uma cidade, o que, por sua vez, "traz consigo impulso em vários setores, como o alimentício, entretenimento, imobiliário, entre outros".

A avaliação desse impacto econômico na cidade de Ituiutaba demonstrou que os bens e serviços mais consumidos pelos 241 estudantes que passaram a residir na cidade, após o ingresso na FACIP/UFU, são os produtos alimentícios e de limpeza, material de papelaria, medicamentos, aluguel de imóvel residencial, utensílios para o lar, festas e bares, táxi, vestuário e acessórios e Internet (Quadro 6). 
Bens e serviços consumidos pelos alunos da FACIP/UFU, residentes nesta cidade, que vieram de outras localidades após o ingresso na instituição

\begin{tabular}{|c|c|c|c|c|c|c|c|c|c|}
\hline \multirow[b]{2}{*}{ Bens e Serviços } & \multicolumn{4}{|c|}{$N^{o}$ de alunos } & \multirow[b]{2}{*}{ Bens e Serviços } & \multicolumn{4}{|c|}{$\mathrm{N}^{0}$ de alunos } \\
\hline & Sim & Não & $\begin{array}{c}\text { Não } \\
\text { Responderam }\end{array}$ & Total & & Sim & Não & \begin{tabular}{|c|} 
Não \\
responderam
\end{tabular} & Total \\
\hline Produtos Alimentícios e de limpeza & 229 & 12 & 0 & 241 & Cinema & 76 & 164 & 1 & 241 \\
\hline $\begin{array}{l}\text { Material de papelaria (caderno, caneta, } \\
\text { papel etc.) }\end{array}$ & 224 & 17 & 0 & 241 & $\begin{array}{l}\text { Serviços Domésticos (lavadeira, } \\
\text { cozinheira, etc.) }\end{array}$ & 71 & 165 & 5 & 241 \\
\hline Medicamentos & 212 & 29 & 0 & 241 & Transporte Coletivo Urbano & 62 & 177 & 2 & 241 \\
\hline Festas e Bares & 199 & 41 & 1 & 241 & Academia & 60 & 179 & 2 & 241 \\
\hline Internet & 187 & 53 & 1 & 241 & Cursos de Idiomas & 60 & 179 & 2 & 241 \\
\hline Táxi & 182 & 57 & 2 & 241 & Hospedagem (hotel, pensionato, etc.) & 46 & 194 & 1 & 241 \\
\hline Aluguel de imóvel residencial & 179 & 62 & 0 & 241 & Auto Escola & 44 & 195 & 2 & 241 \\
\hline $\begin{array}{l}\text { Utensílios para o lar (vasilhas, talheres, } \\
\text { copos, etc.) }\end{array}$ & 177 & 62 & 2 & 241 & Materiais Esportivos & 43 & 197 & 1 & 241 \\
\hline Vestuário e Acessórios (roupas e calçados) & 156 & 85 & 0 & 241 & Bicicleta & 30 & 210 & 1 & 241 \\
\hline Moto Táxi & 131 & 110 & 0 & 241 & Clube & 27 & 212 & 2 & 241 \\
\hline Serviço Médico e Atendimento Hospitalar & 129 & 109 & 3 & 241 & Materiais de Construção & 20 & 219 & 2 & 241 \\
\hline $\begin{array}{l}\text { Material de Informática (cartuchos, } \\
\text { impressoras, computadores etc.) }\end{array}$ & 115 & 126 & 0 & 241 & Advogado & 17 & 220 & 4 & 241 \\
\hline Móveis (sofá, cama, cadeira etc.) & 114 & 125 & 2 & 241 & Instrumento Musical & 17 & 222 & 2 & 241 \\
\hline Revista e Jornal & 112 & 129 & 0 & 241 & Carro & 16 & 222 & 3 & 241 \\
\hline Eletrodoméstico (geladeira, fogão etc.) & 102 & 137 & 2 & 241 & Moto & 15 & 221 & 5 & 241 \\
\hline Celular & 89 & 151 & 1 & 241 & Cursos de Informática & 14 & 225 & 2 & 241 \\
\hline $\begin{array}{l}\text { Serviços Odontológicos, Psicológicos, } \\
\text { Oftalmológicos (etc.) }\end{array}$ & 79 & 161 & 1 & 241 & $\begin{array}{l}\text { Outros (transporte rodoviário } \\
\text { intermunicipal e interestadual) }\end{array}$ & 2 & 0 & 239 & 241 \\
\hline
\end{tabular}

Quadro 6 - Ituiutaba (MG): bens e serviços consumidos pelos alunos da FACIP/UFU, residentes nesta cidade, que vieram de outras localidades após o ingresso na instituição, 2010.

Fonte: PESQUISA DE CAMPO, 2010. Org.: NASCIMENTO, P. A. G., 2010. 
Além de participarem de atividades de ensino, pesquisa e extensão, ressalta-se que os alunos que vieram de outras localidades para Ituiutaba, motivados pela presença da FACIP/UFU, contribuem também para o processo de reestruturação da cidade. $\mathrm{O}$ setor de comércio e serviços tende a ampliar a variedade de produtos, além de passar por manutenções em suas estruturas físicas a fim de atender, principalmente, as demandas dos migrantes universitários.

Por outro lado, os 108 alunos que realizam fluxos diários, de vários municípios vizinhos para Ituiutaba, no período de segunda a sexta-feira e de segunda a sábado, não provocam um impacto econômico tão significativo na cidade como os alunos originários de outras localidades que passaram a residir nela (Quadro 7).

Verificou-se que os bens e serviços mais consumidos em Ituiutaba, pelos estudantes residentes nos municípios vizinhos, são os seguintes: vestuário e acessórios, produtos alimentícios e de limpeza, serviço médico e atendimento hospitalar, medicamentos e materiais de papelaria (Quadro 7).

No entanto, notou-se que alguns bens e serviços, como academia, cursos de informática, aluguel de imóvel residencial e hospedagem, materiais esportivos e de construção têm menor importância entre os elementos consumidos pelos estudantes (abaixo dos 50\%) que realizam fluxos pendulares (Quadro 7). 
Bens e serviços consumidos, nesta cidade, pelos alunos da FACIP/UFU que realizam fluxos pendulares

\begin{tabular}{|c|c|c|c|c|c|c|c|c|c|}
\hline \multirow[b]{2}{*}{ Bens e Serviços } & \multicolumn{4}{|c|}{$\mathbf{N}^{0}$ de alunos } & \multirow[b]{2}{*}{ Bens e Serviços } & \multicolumn{4}{|c|}{ N. de estudantes } \\
\hline & Sim & Não & \begin{tabular}{|c|} 
Não \\
responderam
\end{tabular} & Total & & Sim & Não & $\begin{array}{c}\text { Não } \\
\text { responderam }\end{array}$ & Total \\
\hline Vestuário e Acessórios (roupas e calçados) & 58 & 44 & 6 & 108 & Celular & 15 & 87 & 6 & 108 \\
\hline Produtos Alimentícios e de limpeza & 49 & 53 & 6 & 108 & Carro & 12 & 90 & 6 & 108 \\
\hline Festas e Bares & 46 & 57 & 5 & 108 & Instrumento Musical & 10 & 92 & 6 & 108 \\
\hline Serviço Médico e Atendimento Hospitalar & 46 & 56 & 6 & 108 & Materiais Esportivos & 10 & 91 & 7 & 108 \\
\hline Medicamentos & 45 & 56 & 7 & 108 & Moto & 9 & 93 & 6 & 108 \\
\hline Material de papelaria (caderno, caneta, papel etc.) & 40 & 61 & 7 & 108 & Cursos de Idiomas & 8 & 93 & 7 & 108 \\
\hline Moto Táxi & 35 & 67 & 6 & 108 & Materiais de Construção & 8 & 93 & 7 & 108 \\
\hline $\begin{array}{l}\text { Serviços Odontológicos, Psicológicos, } \\
\text { Oftalmológicos (etc.) }\end{array}$ & 34 & 69 & 5 & 108 & $\begin{array}{l}\text { Hospedagem (hotel, pensionato, } \\
\text { etc.) }\end{array}$ & 7 & 95 & 6 & 108 \\
\hline Táxi & 34 & 67 & 7 & 108 & Advogado & 6 & 96 & 6 & 108 \\
\hline Internet & 24 & 78 & 6 & 108 & Auto Escola & 5 & 97 & 6 & 108 \\
\hline Eletrodoméstico (geladeira, fogão etc.) & 21 & 80 & 7 & 108 & Clube & 5 & 97 & 6 & 108 \\
\hline $\begin{array}{l}\text { Material de Informática (cartuchos, impressoras, } \\
\text { computadores etc.) }\end{array}$ & 21 & 81 & 6 & 108 & $\begin{array}{l}\text { Serviços Domésticos (lavadeira, } \\
\text { cozinheira, etc.) }\end{array}$ & 5 & 97 & 6 & 108 \\
\hline Cinema & 19 & 83 & 6 & 108 & Aluguel de imóvel residencial & 3 & 99 & 6 & 108 \\
\hline Revista e Jornal & 18 & 84 & 6 & 108 & Bicicleta & 3 & 99 & 6 & 108 \\
\hline Utensílios para o lar (vasilhas, talheres, copos, etc.) & 18 & 83 & 7 & 108 & Cursos de Informática & 3 & 99 & 6 & 108 \\
\hline Transporte Coletivo Urbano & 17 & 85 & 6 & 108 & $\begin{array}{l}\text { Outros (biblioteca, salão de } \\
\text { beleza, motel e posto de } \\
\text { combustível) }\end{array}$ & 3 & 0 & 105 & 108 \\
\hline Móveis (sofá, cama, cadeira etc.) & 16 & 86 & 6 & 108 & Academia & 2 & 100 & 6 & 108 \\
\hline
\end{tabular}

Quadro 7 - Ituiutaba (MG): bens e serviços consumidos, nesta cidade, pelos alunos da FACIP/UFU que realizam fluxos pendulares, 2010.

Fonte: PESQUISA DE CAMPO, 2010. Org.: NASCIMENTO, P. A. G., 2010. 
Embora esta pesquisa tenha se limitado à análise da FACIP/UFU, observando os impactos gerados a partir da atração de estudantes, não se pode deixar de considerar, em um estudo mais amplo sobre a área de influência da cidade de Ituiutaba, os fluxos pendulares e o consumo de bens e serviços gerados pelos discentes e funcionários das demais instituições de ensino superior existentes nessa cidade.

Assim, a prestação de serviços de saúde e educação e a atuação de outros órgãos públicos (estaduais e federais) e dos agentes econômicos fazem com que Ituiutaba seja uma importante cidade no contexto regional ${ }^{11}$.

\section{CONSIDERAÇÕES FINAIS}

Os dados apresentados e analisados neste trabalho permitem concluir que:

- Ituiutaba tem uma área de influência que abrange vários municípios da Mesorregião Triângulo Mineiro/ Alto Paranaíba. Entretanto, essa cidade exerce papel mais significativo para os municípios de sua microrregião geográfica e para Centralina, Campina Verde e Monte Alegre de Minas.

- O Estado, sobretudo, pela atuação do governo estadual, é um agente importante na construção do papel regional de Ituiutaba.

O presente estudo, em geral, corrobora o entendimento de que Ituiutaba é uma cidade que desempenha funções urbanas para a sua população e para a dos municípios localizados na sua microrregião e nas proximidades desta ${ }^{12}$.

Este trabalho também apresenta informações e dados que chamam a atenção para processos que fazem parte do presente de Ituiutaba e que, a médio e longo prazo, tendem a promover intensas reestruturações na cidade e no seu papel regional.

O elemento principal dessa dinâmica é a recente implantação de instituições federais de ensino, a Faculdade de Ciências Integradas do Pontal (FACIP/UFU) e o Instituto Federal de Educação, Ciência e Tecnologia do Triângulo Mineiro (IFTM).

A análise da atuação FACIP/UFU, realizada neste estudo, possibilita as seguintes conclusões gerais:

- A presença das instituições federais de ensino superior, por um lado, reforça a área de influência de Ituiutaba historicamente consolidada e, por outro, atua como elemento que 
amplia a capacidade da cidade de atrair pessoas de localidades distantes, geograficamente. Isso está confirmado, sobretudo, pelo fato de que os dados analisados neste estudo demonstram que a atuação da FACIP/UFU não se restringe à escala geográfica microrregional e regional. Essa instituição, até o seu quarto ano de funcionamento, já atraiu alunos de municípios brasileiros localizados nos estados de São Paulo, Goiás, Distrito Federal, Rio de Janeiro, Mato Grosso e Alagoas.

- Entre as mudanças que afetam Ituiutaba têm destaque, também, a chegada de novos moradores (permanentes e temporários) e o aumento do consumo de bens e serviços de naturezas variadas, vinculado diretamente às demandas dos residentes que vieram para essa cidade por causa das instituições de ensino federal.

Entretanto, apesar dos resultados pontuais, apresentados ao longo deste texto, que possibilitam conhecer com detalhes a área de influência de Ituiutaba, formada a partir dos órgãos públicos estaduais e federais e da prestação de serviços de saúde e educação superior, faz-se necessária a realização de outras pesquisas geográficas sobre ela, para se compreender a sua dinâmica sócio-econômica e espacial, no período contemporâneo. Particularmente, são necessários estudos que privilegiem, sobretudo, as mudanças no espaço intraurbano, que também ocorrem associadas à presença das instituições federais de ensino e de outros novos agentes espaciais.

\section{Notas:}

\footnotetext{
${ }^{1}$ A região do Pontal do Triângulo Mineiro é conhecida, localmente, como sendo as áreas localizadas na porção oeste da Mesorregião do Triângulo Mineiro. Em geral, são considerados como parte desta região os municípios das Microrregiões Geográficas de Ituiutaba e de Frutal.

${ }^{2}$ Sobre os agentes econômicos de Ituiutaba e as interações espaciais promovidas por estes, consultar Nascimento e Melo (2010).

3 A metodologia de estudo da ReCiMe divide-se em 4 eixos: I) Ramos de Atividades Econômicas Representativas da Atuação dos Novos Agentes Econômicos; II) Dinâmica Populacional e Mercado de Trabalho; III) Equipamentos e Infra-estruturas; IV) Condições de Moradia. Para maiores informações sobre as variáveis que fazem parte de cada eixo, ver Sposito et al. (2007).

${ }^{4}$ Os trabalhos de campo foram realizados nos seguintes períodos: durante oito dias do mês de janeiro ; no dia 2 de fevereiro; no dia 3 de março; nos dias 21, 24, 25 de maio; e no dia 7 de junho, em 2010, na cidade de Ituiutaba. Realizaram-se entrevistas em 34 órgãos públicos.

${ }^{5}$ Deve-se lembrar que a região de influência de Ituiutaba é constituída pelos seguintes municípios: Cachoeira Dourada, Capinópolis, Gurinhatã, Ipiaçu, Santa Vitória e, São Simão. Apenas Canápolis e Monte Alegre de Minas não se inserem nessa delimitação geográfica (REGIC, 2007).
} 


\footnotetext{
${ }^{6}$ A pesquisa feita com os alunos de graduação da FACIP/UFU não é uma amostra, uma vez que os questionários estruturados e aplicados tiveram a intenção de englobar o maior número possível de estudantes de todos os cursos dessa Unidade Acadêmica.

${ }^{7}$ Estas cotas médicas referem-se aos procedimentos de terapias especializadas, órteses e próteses e materiais especiais.

${ }^{8}$ Vale lembrar que a verba repassada pelos municípios pactuados ao SUS de Ituiutaba é referente a dezembro de 2009, sendo este o mês das cotas médicas oferecidas pelo referido sistema de saúde (apresentadas na Tabela 6).

9 Os aparelhos médicos e os leitos apresentados no quadro 5 envolvem os setores públicos e privado.

${ }^{10}$ Ressalta-se que três estudantes não especificaram o local de origem dos deslocamentos que realizam para Ituiutaba e um estudante de Santa Vitória não informou a periodicidade dos fluxos pendulares.

${ }^{11}$ Sobre os principais agentes econômicos de Ituiutaba, consultar Nascimento e Melo (2010).

${ }^{12}$ Esta idéia já foi apresentada por Amorim Filho, Bueno e Abreu (1982), Oliveira (2003), Nascimento e Melo (2010), entre outros.
}

\section{REFERÊNCIAS}

ALL. Ituiutaba (MG): número de cursos de idiomas, 2010. Disponível em: www.allonline.com.br. Acesso em: 20 jun. 2010.

AMORIM FILHO, Oswaldo Bueno; RIGOTTI, J. I. R. Os limiares demográficos na caracterização das cidades médias. In: ENCONTRO DA ASSOCIAÇÃO BRASILEIRA DE ESTUDOS POPULACIONAIS, 13, 2002, Ouro Preto. Anais... Ouro Preto: ABEP, 2002, p. 220-242. CD-ROM.

AMORIM FILHO, Oswaldo Bueno; BUENO, Maria Elizabeth Taitson; ABREU; João Francisco. Cidades de porte médio e o programa de ações sócio-educativo-culturais para as populações carentes do meio urbano em Minas Gerais. Boletim de Geografia Teorética, Rio Claro, vol. 12, n. 23/24, p. 33-46. 1982.

BRASIL. Conselho Nacional de Secretários de Saúde. Assistência de Média e Alta Complexidade no SUS. Brasília: CONASS, 2007. 248 p.

CCAA. Ituiutaba (MG): número de cursos de idiomas, 2010. Disponível em: www.ccaaituiutaba.com/. Acesso em: 20 jun. 2010.

CORRÊA, Roberto Lobato. Construindo o conceito de cidade média. In: SPOSITO, Maria Encarnação Beltrão (Org.). Cidades Médias: espaços em transição. São Paulo : Expressão popular, 2007. p. 23-33.

CULTURA INGLESA. Ituiutaba (MG): número de cursos de idiomas, 2010. Disponível em: www.culturainglesaituiutaba.com.br. Acesso em: 20 jun, 2010.

DEPARTAMENTO DE INFORMÁTICA DO SISTEMA ÚNICO DE SAÚDE (DATASUS). Equipamentos e serviços de saúde de Ituiutaba e municípios pactuados. Disponível em: w3.datasus.gov.br/. Acesso em: 25 jan. 2010.

FACULDADE DE CIÊNCIAS INTEGRADAS DO PONTAL - FACIP/UFU. Ituiutaba (MG): número de cursos superiores, 2010. Disponível em: www.facip.ufu.br/. Acesso em: 20 jun. 2010. 
FACULDADE DO TRIÂNGULO MINEIRO - FTM. Ituiutaba (MG): número de cursos superiores, 2008. Disponível em: www.ftm.edu.br/. Acesso em: 20 jun. 2010.

FUNDAÇÃO EDUCACIONAL DE ITUIUTABA - FEIT. Ituiutaba (MG): número de cursos superiores, 2010. Disponível em: www.ituiutaba.uemg.br/feit.php. Acesso em: 20 jun. 2010.

INSTITUTO BRASILEIRO DE GEOGRAFIA E ESTATÍSTICA - IBGE. Contagem da população de Ituiutaba, 2007. Disponível em: www.ibge.gov.br. Acesso em: 16 mar. 2010.

Regiões de Influência das cidades, 2007. Disponível em: < www.ibge.gov.br/home/geociencias/geografia/regic.shtm?c=6. Acesso em: 18 mar. 2010 .

População estimada dos municípios pactuados ao SUS de Ituiutaba (MG), 2009. Disponível em: www.ibge.gov.br/. Acesso em: 04 fev. 2010.

GEOPROCESSAMENTO EM MINAS GERAIS - GEOMINAS. Base cartográfica do município de Ituiutaba e mesorregião do Triângulo Mineiro/Alto Paranaíba e estado de Minas Gerais, 2010. Disponível em: www.geominas.mg.gov.br/. Acesso em: 5 mar. 2010.

GOOGLE MAPS. Distância dos fluxos de alunos de Capinópolis (MG) e São Simão (GO) para Ituiutaba (MG), 2010. Disponível em: www.maps.google.com.br/maps. Acesso em: 20 out. 2010.

INSTITUTO FEDERAL DE EDUCAÇÃO, CIÊNCIA E TECNOLOGIA DO TRIÂNGULO MINEIRO - IFTM. Ituiutaba (MG): número de cursos técnicos, 2010. Disponível em: www.iftriangulo.edu.br/ituiutaba/. Acesso em: 20 jun. 2010.

INSTITUTO NACIONAL DE ESTUDOS E PESQUISAS EDUCACIONAIS ANISIO TEIXEIRA - INEP. Ituiutaba (MG): número de matrículas das escolas públicas e privadas, 2000 a 2008. . Disponível em: www.inep.gov.br/. Acesso em: 20 out. 2009.

NASCIMENTO, Plínio Andrade Guimarães do; MELO, Nágela Aparecida de. Ituiutaba (MG): os agentes econômicos e a (re)estruturação da cidade na rede urbana regional. Revista Horizonte Científico, Uberlândia, v. 4, n.1, p. 1-35. 2010a.

NASCIMENTO, Plínio Andrade Guimarães do; MELO, Nágela Aparecida de. Ituiutaba (MG): análise da sua área de inflluência a partir da atuação de órgãos públicos estaduais e federais no ano de 2010b. Disponível em: www.agb.org.br/evento/download.php?idTrabalho=1362. Acesso em: 20 nov. 2010.

OLIVEIRA, Bianca Simoneli de. Ituiutaba na rede urbana tijucana: (re) configurações sócio-espaciais de 1950 a 2003. 208f. Dissertação (Mestrado em Geografia). Instituto de Geografia, Universidade Federal de Uberlândia, Uberlândia, 2003.

SANTOS, Milton.; SILVEIRA, María Laura. O Brasil: território e sociedade no início do século XXI. 9.ed. Rio de Janeiro: Record, 2006. 473p.

SANTOS, M. A urbanização brasileira. São Paulo: HUCITEC, 1993. 
SECRETARIA DE ESTADO DE SAÚDE DE MINAS GERAIS (SES/MG). Microrregião de saúde de Ituiutaba (2009). Disponível em: www.saude.mg.gov.br/. Acesso em: 16 mar. 2010.

SECRETARIA DE ESTADO DE SAÚDE DE MINAS GERAIS - SES/MG. Ituiutaba (MG): cotas médicas e verba repassada pelos municípios pactuados ao SUS desta cidade, 2009. Disponível em: www.saude.mg.gov.br/. Acesso em: 16 mar. 2010.

SERVIÇO NACIONAL DE APRENDIZAGEM COMERCIAL - SENAC. Ituiutaba (MG): número de cursos técnicos, de capacitação e educação à distância, 2010. Disponível em: www.mg.senac.br/. Acesso em: 20 jun. 2010.

SERVIÇO NACIONAL DE APRENDIZAGEM INDUSTRIAL - SENAI. Ituiutaba (MG): número de cursos técnicos, de aprendizagem e, qualificação e aperfeiçoamento, 2010. Disponível em: www.senai.br/. Acesso em: 20 jun. 2010.

SILVA, Clayton Borges da; RAMIRES, Julio Cesar de Lima. O Hospital de Clínicas da UFU e sua importância na definição da macrorregião Triângulo Norte. In: RAMIRES, Julio Cesar de Lima (Org). Geografia da Atenção à Saúde em Uberlândia. Uberlândia: Assis Editora, 2009. p. 41-62.

SILVA, Kássia Nunes da; RAMIRES, Julio Cesar de Lima. O pólo de serviços de saúde em Uberlândia: um cluster em formação. In: RAMIRES, Julio Cesar de Lima (Org). Geografia da Atenção à Saúde em Uberlândia. Uberlândia: Assis Editora, 2009. p. 11-39.

SOARES, Beatriz Ribeiro; RAMIRES, Julio Cesar de Lima; OLIVEIRA, Hélio Carlos Miranda de; MELO, Nágela Aparecida de; SOUZA, Marcus Vinícius Mariano de; RIBEIRO FILHO, Vitor. Uberlândia (MG): leituras geográficas de uma cidade média em transição. In: ELIAS, Denise; SPOSITO, Maria Encarnação Beltrão; SOARES, Beatriz Ribeiro (Orgs). Agentes econômicos e reestruturação urbana e regional: Tandil e Uberlândia. 1. ed. São Paulo: Expressão Popular, 2010. p. 159-288.

SOARES, Beatriz. R.; LUZ, Janes. S.; MELO, Nágela. A. A importância da dimensão regional na análise da cidade média goiana. In: ENCONTRO NACIONAL DA ANPEGE, 6., 2005. Fortaleza... Anais. Fortaleza: ANPEGE/UFC, 2005. 1 CD rom.

SOARES, Beatriz Ribeiro. Uberlândia: da cidade jardim ao portal do cerrado imagens e representações no Triângulo Mineiro. 1995. 366 f. Tese (Doutorado em Geografia Humana) - Faculdade de Filosofia, Letras Ciências Humanas, Universidade de São Paulo, São Paulo, 1995.

SOUZA, Marcus Vinicius Mariano de; BRUMES, Karla Rosário. Migrações urbanas, causas e implicações: uma análise da migração educacional em Uberlândia (MG). In: SOARES, Beatriz Ribeiro; OLIVEIRA, Hélio Carlos Miranda de; MARRA, Thiago Batista (Orgs). Ensaios Geográficos. Uberlândia: UFU/PET-Geografia, 2006. p. 137148.

SPOSITO, Maria Encarnação Beltrão et al. O estudo das cidades médias brasileiras: uma proposta metodológica. In: SPOSITO, Maria Encarnação Beltrão (Org). Cidades Médias: espaços em transição. São Paulo: Expressão Popular, 2007. p. 35-67. 
SPOSITO, Maria Encarnação Beltrão. As cidades médias e os contextos econômicos contemporâneos. In: SPOSITO, Maria Encarnação Beltrão (Org). Urbanização e cidades: perspectivas geográficas. Presidente Prudente: [s.n], 2001. p. 609-643.

UNIVERSIDADE NORTE DO PARANÁ - UNOPAR. Ituiutaba (MG): número de cursos superiores, 2010. Disponível em: www.unoparvirtual.com.br/. Acesso em: 20 jun. 2010.

Enviado para publicação em novembro de 2011.

Aceito para publicação em dezembro de 2011. 